\title{
CLÍNICA DA ATIVIDADE E CARTOGRAFIA: CONSTRUINDO METODOLOGIAS DE ANÁLISE DO TRABALHO
}

\author{
Danielle Vasconcelos Teixeira e Maria Elizabeth Barros de Barros \\ Universidade Federal do Espírito Santo, Vitória, Brasil
}

\begin{abstract}
RESUMO: As questões formuladas no artigo foram disparadas por experiências vividas ao longo dos últimos anos em pesquisas que partem do princípio de que a temática saúde e trabalho, como objeto de investigação científica, tem uma especificidade que não pode ser tomada com posturas de exterritorialidade no que diz respeito à relação do pesquisador e do objeto a ser investigado. As questões dos mundos do trabalho não podem estar baseadas apenas em quadros analíticos construídos a partir de um distanciamento da complexidade engendrada onde o trabalho acontece. Propõe-se uma direção metodológica de pesquisa que articula investigação e intervenção na direção do diálogo, da interlocução entre os diferentes saberes - disciplinares ou não - com o objetivo de potencializar estratégias utilizadas pelos trabalhadores para lidar com a variabilidade das situações de trabalho. Com esse objetivo, traz a contribuição da Clínica da Atividade como importante ferramenta metodológica.
\end{abstract}

PALAVRAS-CHAVE: análise do trabalho; clínica da atividade; cartografia.

\section{CLINIC OF ACTIVITY AND CARTOGRAPHY: CONSTRUCTING METHODOLOGIES FOR ANALYSIS OF THE WORK}

\begin{abstract}
The issues raised in this article were incited by experiences lived in the last years in studies that take as principle that Health and Work, as scientific research objects, have specificities that can not be considered from exterritoriality positions, regarding the relationship between the researcher and the object being investigated. Issues about work can not be based only on analytical views in a distant way of the complexity engendered where work happens. This article proposes a methodological direction of research that articulates research and intervention in a direction to dialogue, to the interchange between different knowledges - disciplinary or not - in order to strengthen strategies used by workers to deal with the variability of work situations. With that purpose, it brings the contribution of the Clinic of Activity as an important methodological tool.
\end{abstract}

KEYWORDS: analysis of the work; clinic of activity; cartography.

As questões que formulamos neste artigo foram disparadas, em grande parte, pelas experiências que temos vivido ao longo dos últimos anos nos municípios da Grande Vitória (ES), que integram as pesquisas do Núcleo de Estudos e Pesquisas em Subjetividade e Políticas (NEPESP), do Departamento de Psicologia da UFES. Nessas pesquisas temos focado as condições de trabalho nas escolas da Grande Vitória, visando a articular pesquisa e intervenção na direção do diálogo, da interlocução entre os diferentes saberes - disciplinares ou não - com o objetivo de potencializar as estratégias utilizadas pelos trabalhadores da educação para lidar com a variabilidade das situações vividas nessas escolas.

Esse percurso tem possibilitado a formulação de muitas questões sobre os processos de trabalho no contemporâneo, o que tem nos ajudado a avançar na construção de metodologias para a análise desses processos. Como trabalhar num contexto em que a lógica hegemônica de funcionamento tenta sufocar as possibilidades de criação, de vida mais potente, de aprendizagem inventiva, de produção de saúde, de cogestão? Como podemos contribuir para potencializar a construção de outros modos de existência que ampliem a vida? ${ }^{2}$ Que estratégias metodológicas podemos utilizar a partir desses objetivos? Como construir metodologias de análise que sejam ferramentas-intercessoras para o processo de transformação do vivido nos locais de trabalho que buscam constranger a atividade dos trabalhadores? Partindo dessas questões, o presente texto busca trazer alguns elementos que possam contribuir na formulação de estratégias metodológicas para análise das situações de trabalho e promoção de saúde.

A produção científica sobre os mundos do trabalho tem priorizado a identificação de quadros psicopatológicos, e as pesquisas desenvolvidas neste campo têm se utilizado, predominantemente, de metodologias epidemiológicas que destacam o sofrimento experimentado nos locais de trabalho. Tais caminhos 
investigativos são importantes, mas consideramos que apenas identificar quadros psicopatológicos associados ao trabalho, privilegiando os processos de sofrimento e adoecimento, pode não ser suficiente quando temos como meta a transformação da situação vivida hoje nos ambientes laborais.

A direção de pesquisa que temos privilegiado indica outra opção metodológica, pois não focaliza apenas o sofrimento provocado pelas situações de trabalho, mas principalmente concentra-se nos movimentos que os trabalhadores fazem para criar e recriar seu trabalho. Diversos estudos têm sido realizados nessa direção ético-política, apontando um campo bastante fértil de investigação e de intervenção. Investigações que partem do princípio de que a temática saúde e trabalho, como objeto de investigação científica, tem uma especificidade que não pode ser tomada com posturas de exterritorialidade (Schwartz, 2004) no que diz respeito à relação do pesquisador com a análise desse objeto. As questões dos mundos do trabalho não podem estar baseadas apenas em quadros analíticos construídos externamente,

distante da complexidade engendrada onde a história singular acontece.... Essa perspectiva epistemológica e metodológica apóia-se na compreensão que temos do que é viver e trabalhar e na avaliação de que os limites do conhecimento científico sobre saúde e trabalho só podem ser superados se confrontados e estimulados pelos desafios e pelas indagações advindas da experiência daqueles que vivem as relações que investigamos (Brito \& Atayde, 2003, p. 240).

Vislumbramos o diálogo como um caminho necessário para que se efetive um debate entre os saberes científicos e os saberes advindos da experiência quando o tema é análise do trabalho, uma vez que "a questão central é o entendimento que temos do que é o trabalho e de que tipo de interlocução estabelecemos nas ações com os trabalhadores e trabalhadoras." (Brito \& Atayde, 2003, p. 240). Buscamos ferramentas que nos permitam um afastamento do lugar de "especialista" sobre os mundos do trabalho, daqueles que falam pelos trabalhadores, e, com esse objetivo, partimos de uma concepção de trabalho formulada por algumas abordagens desenvolvidas na França e, em especial, na Clínica da Atividade, da qual escolhemos Yves Clot como interlocutor. Tal abordagem segue na direção de nosso entendimento sobre o modo como tem se colocado a questão do trabalho atualmente.

Pensar uma Psicologia do Trabalho nessa direção significa assumir uma atitude que desloca o analista do trabalho para um não-lugar, um estar em trânsito, estar entre, em que o trabalho passa a ser entendido como um "encontro entre corpos.... A análise do trabalho, em conseqüência, só pode ser exercida em um espaço coletivo, partindo desta experiência compartilhada, na qual conhecer e fazer já não se diferenciam" (Maia, 2006, p. 2).

Uma Psicologia do Trabalho, então, em que as dimensões éticas, política e estética não mais se separam e outra compreensão do trabalhar se coloca, ou seja, como uma atividade inventiva que "transborda por todos os lados uma execução técnica de tarefas, fazendo-nos entender que o trabalhador não é um mero autômato reprodutor de normas prescritas e técnicas de trabalho predeterminadas" (Maia, 2006, p. 3).

Clot (2006) entende a atividade como algo mais do que a tarefa realizada passível de descrição para fins de análise, pois coloca os conflitos do real como fazendo parte da atividade de trabalho. Entendida como se realizando entre intenções concorrentes, a atividade exige a mobilização física e psíquica do trabalhador em face de um meio em constante variação. Assim, para realizar o seu trabalho, o sujeito faz escolhas, antecipações, improvisações e toma decisões, que convocam a subjetividade no trabalho, o que se efetiva como realização de desvios inventivos que permitem que a tarefa prescrita possa ser realizada. Ao discutir a hipótese da função psicológica do trabalho, Clot (2006) faz uma crítica da dicotomia que é feita entre vida no trabalho e vida fora do trabalho. Considera o sofrimento do ponto de vista da atividade como efeito de uma atividade contrariada e até reprimida. Trata-se, nesse caso, de uma amputação do poder de agir. Esse "poder de agir" tem se mostrado como um operador conceitual importante na Clínica da Atividade, pois afirma o potencial inventivo próprio da vida, que no trabalho humano não se deixa aprisionar pela lógica capitalista. Nesse sentido, e, diferentemente das críticas ao taylorismo do início do século direcionadas à fadiga ocasionada pela intensificação do gesto, Yves Clot (2006) considera, a partir de Wallon, que Taylor não teria exigido demais dos trabalhadores, e sim, demasiado pouco. Amputar o trabalhador de sua iniciativa acaba por desembocar

num esforço mais dissociativo, mais fatigante e mais extenuante que se possa encontrar ..., o esforço não é só o que este homem faz para seguir a cadência, é igualmente aquele com que ele deve consentir para reprimir sua própria atividade (Wallon, citado por Clot, 2006, p. 14).

Entendemos que é essa tentativa de imobilizar os movimentos de criação do trabalhador que produz a naturalização da relação dor-desprazer-trabalho, pois "A calibração dos gestos é uma amputação do movimento" (Clot, 2006, p. 14). A dor vem, então, do esforço deste trabalhador para colocar entre parênteses a riqueza de suas atividades.

É esse gesto ao mesmo tempo prescrito e interdito que mais custa ao trabalhador. Sem poder aboli-lo, procura-se pôr sua atividade entre parênteses. Na rea- 
lidade, ela é somente levada a gerar 'sofrimento'.... A fusão imaginária do homem e da máquina desemboca então paradoxalmente na impossível identificação do sujeito com os atos a ele prescritos.... é impossível, para a produção, absorver toda a atividade pessoal do sujeito em operações elementares. Ninguém tem o poder de aniquilar a atividade pessoal do trabalhador. Na melhor das hipóteses, ela é deslocada ou alienada (Clot, 2006, p. 14).

Dessa forma, o taylorismo impõe um movimento que exige o mínimo de intervenção do trabalhador, tentando privá-lo de sua iniciativa durante seu dia de trabalho. Entretanto, mesmo com sua proibição, a atividade não pode ser eliminada. E é aí que se encontram os conflitos. Da mesma maneira, percebemos como o sofrimento resulta também das possibilidades que os trabalhadores experimentam, mas que não podem ser vividas, daquilo que não se pode fazer na realização de suas tarefas. Quando uma determinada organização não consegue atender às exigências dos trabalhadores, a atividade pode ser impedida, uma vez que não se considera a experiência dos trabalhadores que elas empregam.

Então, indagamos com Clot (2006), como compreender a atividade, como abordá-la e, sobretudo, como explicar que o trabalho, nessas condições, não só conserva sua função psicológica na vida pessoal e social, como também a desenvolve? O autor nos indica que a atividade contrariada deve estar no centro das análises nesta Psicologia do Trabalho que estamos propondo a partir da Clínica da Atividade, haja vista que se destaca a importância da subjetividade no curso da atividade, que não pode ser desprezada na ação profissional. Para o sujeito, todos os objetos, as ferramentas, os signos e a atividade dos outros com relação a ele são, primeiramente, fonte de produção de subjetividade, e só depois se tornam meios a serviço da sua atividade. Essa produção subjetiva consiste em poder se apropriar do mundo, em fazer dele um mundo "para si" a fim de reformulá-lo e criá-lo.

É nesse sentido que, para além dos objetivos tayloristas, a exploração no mundo do trabalho hoje apresenta novas exigências quanto ao uso de capacidades subjetivas da força de trabalho, ou seja, cada vez mais e de forma sistemática, convoca-se a subjetividade no trabalho.

É a partir desse debate que insistimos, portanto, na importância da formulação de uma metodologia que possibilite a ampliação do poder de ação do trabalhador de forma a tornar possível um modo de fazer pesquisa em que os trabalhadores participem como protagonistas do processo de investigação. É nessa direção éticopolítica que encontramos pistas para a construção de estratégias metodológicas que possam viabilizar a construção de relações inventivas e prazerosas ${ }^{3}$ com o trabalho. A luta contra o sofrimento para compreendertransformar as relações entre trabalho e subjetividade não é, neste contexto, priorizada, porque esse papel cabe à própria atividade, vista como uma fonte permanente de recriação de novas formas de viver, de viver com o outro. Logo, esse processo se opera, também, a partir de um plano coletivo, denominado por Clot (2006, p. 33) de "dimensão social" da atividade:

Devemos nos voltar a essa dimensão do problema.... devemos recorrer à heterogeneidade dos mundos sociais, aos conflitos das normas, à pluripertinência dos sujeitos a fim de poder situar-nos nas fontes da ação. Aqueles que trabalham são necessariamente emaranhados nesses 'universos contextuais'.

O trabalho tomado do ponto de vista da atividade, portanto, porta um paradoxo, uma vez que, ao exceder por todos os lados as relações de prescrição, constitui-se como uma maneira própria que o trabalhador encontra de singularizar o coletivo e, ao mesmo tempo, de coletivizar sua singularidade (Maia, 2006). Estamos afirmando que existe no curso da atividade um processo de coletivização e singularizarão simultâneo, que faz emergir o que entendemos como trabalhador e como trabalho, uma relação em fundação constante.

Mas, quais são as noções de coletivo e de subjetividade utilizadas neste texto a partir das quais dialogamos com a Clínica da Atividade? De acordo com uma lógica dicotômica, o coletivo é identificado com o social, numa dimensão da realidade que se opõem à dimensão individual. Entendido dessa maneira, o coletivo se confunde com instâncias sociais, como comunidades, povo, massa e no que diz respeito à dinâmica de interações individuais ou grupais.

Em outra direção, estaremos nos apoiando nas ideias de Escossia e Kastrup (2005), quando estas tomam as abordagens de Gilles Deleuze e Félix Guattari sobre essa problemática a fim de propor um conceito de coletivo que não se reduz ao social ou à coletividade, tampouco a um nível de interações sociais. O conceito de coletivo surge aqui ressignificado, entendido como plano de coengendramento e de criação, superando a referida dicotomia e uma lógica que toma os seres e as instituições como dados a priori, sem levar em conta os processos que os engendram. Conceber um conceito de coletivo para além dessas dicotomias, historicamente constituídas, significa dar visibilidade a uma outra lógica - uma lógica atenta ao engendramento, ao processo que antecede, integra e constitui os seres. Conforme Escossia e Kastrup (p. 298):

Os objetos não causam nem determinam nada, ao contrário, eles são determinados, produzidos pela relação. Podemos reter então que os conceitos de prática e de relação remetem a um plano produtor de mundo e de 
sentido, que engendra os termos, sejam sujeitos ou objetos, assim como as próprias dicotomias.

Este plano coletivo não se reduz ao social totalizado, e seu funcionamento não pode ser apreendido através das dinâmicas das relações interindividuais ou grupais, uma vez que estas acontecem entre seres já individuados. As autoras referenciadas, citando Deleuze e Parnet (1998), apontam a noção de agenciamento como a que lhes parece mais apropriada para definir o funcionamento deste plano coletivo.

Agenciar é estar no meio, sobre a linha de encontro de dois mundos. Agenciar-se com alguém, com um animal, com uma coisa - uma máquina, por exemplo - não é substituí-lo, imitá-lo ou identificar-se com ele: é criar algo que não está nem em você nem no outro, mas entre os dois, neste espaço-tempo comum, impessoal e partilhável que todo agenciamento coletivo revela (Escossia \& Kastrup, 2005, p. 303).

A relação aqui é pensada como agenciamento, como um modo de funcionamento de um plano coletivo, que surge como plano de criação, de coengendramento dos seres. Plano coletivo, portanto, relacional, plano de produção de subjetividade, entendida como resultado de um entrecruzamento de determinações coletivas de várias espécies, não só sociais, mas econômicas, tecnológicas, perceptivas, de mídia, de sensibilidade, e assim por diante. Subjetividade, então, que não é sinônimo de indivíduo, sujeito ou pessoa e, sim, processos de subjetivação sempre coletivos, na medida em que agenciam estratos heterogêneos do ser. Ainda, segundo Escossia e Kastrup (2005, p. 303):

Podemos até falar em subjetividades individuais e subjetividades coletivas. Individuais, porque "em certos contextos sociais e semiológicos a subjetividade se individua" (Guattari, 1992, p. 19). Coletivas, porque "em outras condições, a subjetividade se faz coletiva, o que não significa que ela se torne por isso exclusivamente social" (Guattari, 1992, p. 19-20). Mesmo quando se individua em um sujeito, ela não é individual no sentido de privada, conforme ressalta Deleuze: de uma multiplicidade que se desenvolve para além do indivíduo.

Portanto, não podemos afirmar a equivalência entre coletivo e conjunto ou somatório de pessoas. $\mathrm{O}$ coletivo é impessoal, é plano de coengendramento dos indivíduos e da sociedade. Coletivo pensado "de maneira mais múltipla, acentrada, calcada, sobretudo no jogo entre as singularidades e o comum, e na potência ampliada da composição - sempre levando em conta o plano de consistência" (Pelbart, p. 11) e singularidade que não reivindica uma identidade, que constitui uma multiplicidade inconstante e que "declinam toda identidade e toda condição de pertinência, mas manifestam seu ser comum" (Pelbart, p. 11). É no entendimento de que o modo-indivíduo é um, e não o único modo de vida, que nos apropriamos da noção de subjetividade. Subjetividade como processo múltiplo e provisório de construção e desfazimento de modos de vida. Processos de subjetivação que colocam em funcionamento subjetividades várias, produzidas a partir do plano coletivo, e que são tomadas como uma identidade no seu caráter mais imutável.

A noção de subjetividade não se confunde, aqui, com aquela de indivíduo, exatamente, por romper com a lógica que produz este último, por não estar na ordem da intimidade e da particularidade de cada um. Falamos, ao contrário, de subjetividade como uma teia de aspectos desejantes-políticos-econômicos-científicostecnológicos-familiais, e também aspectos singulares da vivência de cada um, orgânicos, perceptivos, afetivos. Trata-se, portanto, de modos de subjetivação que põem em funcionamento formas de pensar, de trabalhar, de amar (Rolnik \& Guattari, 2005). Formas de pensar, agir e viver que não pertencem exclusivamente a um grupo de trabalhadores, que não constituem sua identidade, uma natureza, mas construídas histórica e socialmente, abertas para a criação de outros/novos processos subjetivos que possam pôr em funcionamento subjetividades mais potentes. Se os modos de produção de subjetividade correspondem a modos de experimentação e de construção de realidade comprometidos com modos de criação de si e criação do mundo, podem funcionar como potencializadores da construção de novos modos de existência. Então, uma metodologia de análise do trabalho, tomada a partir dessas concepções de coletivo e de subjetividade, aposta na produção de novas subjetividades nos processos de trabalho abertas a esse plano coletivo, não individual.

\section{Clínica da Atividade como Clinamen}

Os acoplamentos conceituais entre a Clínica da Atividade e a dimensão ético-política das propostas de Gilles Deleuze e Felix Guattari sobre subjetividade nos levam, ainda, a um outro desafio: qual o conceito de clínica que comparece quando falamos de uma Clínica da Atividade? Qual o sentido de uma prática clínica que busca a produção de outros modos de subjetivação e outras formas de subjetividade nos mundos do trabalho? Como produzir uma torção nas formulações, no campo da clínica, que se voltam para uma perspectiva de subjetividade, como sinônimo de indivíduo, sujeito ou pessoa? Que estratégias construir para a afirmação de uma Clínica da Atividade que toma os processos de subjetivação nos processos de trabalho como sempre coletivos, agenciados em estratos heterogêneos do ser? Como não reduzir as práticas nesse âmbito a uma clínica do indivíduo? 
Segundo Benevides de Barros (2002), historicamente, a clínica tem se constituído como um modelo médico de "inclinar-se sobre o paciente", na maioria das vezes num modelo de atendimento individual. Mas o sentido da clínica não se reduz a esse movimento do inclinar-se sobre o leito do doente, como mostra a seguinte análise proposta a partir do sentido etimológico das palavras:

derivada do grego klinikos ("que concerne ao leito"; de klíne, "leito, repouso"; de klino "inclinar, dobrar"). Mais do que essa atitude de acolhimento de quem demanda tratamento, entendemos o ato clínico como a produção de um desvio (clinamen), na acepção que dá a essa palavra a filosofia atomista de Epicuro (1965). Esse conceito da filosofia grega designa o desvio que permite aos átomos, ao caírem no vazio em virtude de seu peso e de sua velocidade, se chocarem articulando-se na composição das coisas. Essa cosmogonia epicurista atribui a esses pequenos movimentos de desvio a potência de geração do mundo. É na afirmação desse desvio, do clinamen, portanto, que a clínica se faz (Barros, Benevides de Barros \& Passos, 2001, p. 93).

Conflitos, desvios, desestabilização, essa concepção de clínica parece-nos uma ferramenta conceitual estratégica quando tomamos os mundos do trabalho como variabilidade e como multiplicidade. Por essa razão pensamos que o trabalho, como uma demanda de análise, convoca uma ação clínica e, nessa direção, não pode ser pensado fora desta situação crítica, marcada por sua instabilidade. A clínica como experiência de desvio, do clinamen, é aquela que faz bifurcar um percurso de vida na criação de novos territórios existenciais, novos processos de trabalho.

Nesse sentido, para nós, uma clínica da produção da subjetividade não busca meramente a solução de problemas, mas a criação de novas questões, numa experimentação analítica das formas instituídas. E, assim, a clínica deve se dar sempre numa relação com acontecimentos que ultrapassam a vivência individual, abrindo-se para a história, para a política, para o plano coletivo. Uma clínica histórica que indica um plano de engendramento da realidade. Uma clínica comprometida com este plano de produção sempre coletivo, indissociável do domínio da produção de subjetividade. Nessa perspectiva, a clínica se dá num espaço a ser construído, diz respeito a uma outra clínica, clínica da diferença, da experimentação, de práticas que são sempre social e historicamente construídas.

Clínica da Atividade, portanto, como uma política da produção de subjetividade, da criação de si, como clinamen, que não só produz desvios como também se desvia em seus percursos, produzindo bifurcações, desestabilizando o já-dado, nos fornecendo potência de intervenção nos mundos do trabalho. Se afirmamos que a ampliação do poder de ação do trabalhador é o principal objetivo do método proposto pela Clínica da Atividade, consideramos que essa ampliação exige a produção de novas formas-subjetividade, a produção de sujeitos capazes de inventar maneiras de enfrentar as situações, confrontando-se com sua própria experiência, bem como com a de outros, já que, na Clínica da Atividade, a mudança deve se efetivar a partir de uma troca entre conceitos e experiências, tendo como protagonistas os trabalhadores.

Assim, o principal analista da atividade de trabalho deve ser o próprio trabalhador, e não um especialista. O psicólogo do trabalho precisa se colocar como um apoio ao deslocamento do trabalhador para o lugar de analista de sua própria atividade. A posição de protagonista atribuída ao trabalhador é um dos pontos que faz dessa abordagem uma metodologia da análise do trabalho e, ao mesmo tempo, de formação. A formação se dá, para o trabalhador, com a renovação ou ampliação de seus recursos para desenvolver suas atividades cotidianas, inseridas numa nova visão das relações que compõem seu trabalho, entendido como um processo concomitantemente coletivo e singular, processo disruptivo de afirmação de outras maneiras de ser, de outras sensibilidades (Rolnik \& Guattari, 1989), de criação e recriação da história de um ofício.

Ao vincular atividade e subjetividade, Clot busca apresentar uma Psicologia do Trabalho mais sensível aos processos de produção de subjetividade que se dá no curso da ação no trabalho. Por isso, intervindo na atividade, estamos intervindo nos modos de subjetivação.

Reafirmamos, então, que este diálogo entre as propostas de Clot para uma Clínica da Atividade e as concepções conceituais e metodológicas aqui evocadas a partir das formulações de Deleuze e Guattari é uma via estratégica para a afirmação da potência do trabalho como capacidade da vida em diferir, em produzir o novo, em criar sujeitos e mundos. Trata-se de proposições conceituais que se comunicam quando afirmam este movimento de criação dos humanos, nos auxiliando a pensar a questão da atividade e da subjetividade no trabalho, e nesse processo, nos ajudam na formulação de um outro modo possível de atuação em Psicologia do Trabalho.

Nesta direção, tomar o trabalho pela via dos processos de subjetivação é afirmar que os trabalhadores são os protagonistas desse processo de criação. É intervir, clinicamente, confrontando-os com sua atividade laboral. Acompanhando Clot (2006), diríamos que o trabalho exerce na vida do trabalhador uma função psicológica específica. E isso, precisamente, em virtude do fato de ele ser uma atividade dirigida. Esse conceito está no centro da renovação proposta por Clot (2006) 
em termos de Psicologia do Trabalho, pois sua proposta é que esta seja a unidade elementar de análise.

O trabalho é aí considerado como uma situação de conflito que recebe sempre soluções transitórias. Esse conflito é o que dá à atividade sua dinâmica vital. A análise da atividade dirige-se, então, não apenas ao procedimento realizado, mas também às intenções que levaram àquelas escolhas. Há uma relação, a ser analisada, entre as preocupações do trabalhador e suas ocupações.

A atividade de trabalho é dirigida e também situada, sempre singular, sendo a recriação de situações o que a constitui. A busca de uma forma de agir pelo sujeito consiste na busca de uma forma de agir que incorpora a ação do outro e a ação prescrita. Portanto, o trabalho é tido como uma atividade dirigida triplamente em seu desenvolvimento: dirigida pelo sujeito, para o objeto e para a atividade dos outros, com mediação de um gênero profissional.

O conceito de gênero, forjado no âmbito da Clínica da Atividade, refere-se a algumas dimensões da vida coletiva do trabalho, "em comum", um componente impessoal, genérico, que não diz respeito a ninguém especificamente. Refere-se aos antecedentes sociais da atividade, às regras coletivas da profissão que formam uma memória impessoal, que dá consistência à atividade, fornecendo modelos de agir, de começar e terminar uma atividade, oferecendo recursos para enfrentar situações que são generalizadas num ofício.

O gênero é, ao mesmo tempo, uma referência coletiva e meio de expressão de cada trabalhador. Funciona como uma memória impessoal, um instrumento que faz existirem as atividades fora de sua realização em situação. É o que as prepara, sustenta e orienta. Por meio do acesso ao gênero, o trabalhador desenvolve a competência profissional, seu estilo, que torna possível a atividade, mas não o faz sem que, simultaneamente, expanda o gênero profissional com seu saber-fazer singular. Assim, a atividade deve ser entendida como uma ação sempre em processo, uma mescla indissociável de singular e coletivo.

Por meio deste conceito de atividade que se processa pelo acesso a um gênero, sempre plural, é que pensamos num trabalho sempre vivo, no qual está presente a produção de subjetividade, tornando o trabalhador, ao mesmo tempo, criador e criação de seu modo de trabalhar.

As normas que constituem o gênero das atividades, requeridas em cada situação, devem ser vistas mais como um movimento do que como um estado. As regras do gênero se tornam visíveis quando este é perturbado, quando é reavaliado pelos estilos de cada trabalhador, uma estilização de técnicas em circulação num ofício. Esse trabalho social prévio à ação forma o gênero deste ofício. Trata-se de uma pré-atividade, algo dado a ser recriado na ação, convenções que são tanto recursos quanto constrangimentos a essa ação.

O estilo, que cada trabalhador imprime no percurso de sua atividade, participa da renovação do gênero, o qual nunca se pode dar por acabado. Ele vive das contribuições estilísticas que o reavaliam constantemente, que lhe dão sua dinâmica. Os gêneros momentaneamente estabilizados são um meio para se apropriar do trabalho, saber como agir, evitando errar sozinho. O gênero marca o pertencimento a um grupo e orienta a ação. É o que permite que duas pessoas que não se conhecem pareçam ter trabalhado juntas anteriormente (Clot, 2006).

Para a Clínica da Atividade, o trabalho só potencializa a produção de subjetividade quando permite que o sujeito entre no mundo do trabalho cujas regras sejam tais que ele possa se apropriar delas. Sem esse comum para "dar-lhe um corpo vivo" o trabalho deixa cada trabalhador diante de si mesmo.

O estilo, portanto, não tem nada a ver com um atributo psicológico invariante. Situa-se sempre no âmbito do gênero ou no ponto de colisão entre as variantes do gênero, às quais recorre alternativamente, a depender do momento. $\mathrm{O}$ estilo é constituído de múltiplas vozes que "se defrontam para constituir a singularidade de um enunciado, de um texto, de uma autoria." (Brait, 2007, p. 79). Portanto, o estilo não pode ser reduzido a uma forma subjetividade, "considerada como o que há de exclusivamente particular, individual, pessoal, características que se tornaram, para o senso comum e para boa parte da estilística clássica/tradicional, sinônimo de estilo" (Brait, 2007, p. 79). Paradoxalmente, o estilo tem uma dimensão particular, mas é resultante da multiplicidade de experiências vividas, não se expressa por traços que identificam o trabalhador.

Cada trabalhador pertence simultaneamente a diversos gêneros dentro do mesmo ofício. Os estilos são a reformulação dos gêneros em situação, transformandoos em recursos para a ação. O gênero, estando a serviço dos sujeitos nas situações de trabalho, retroage sobre os estilos, é a base da estilização da atividade. Aqueles que agem são também objetos dessa ação. O trabalho de estilização dos gêneros faz com que esses se transformem e se desenvolvam. Os gêneros se mantêm vivos graças à sua recriação pelos estilos. Logo, são essas relações que se tornam recursos para o desenvolvimento tanto do gênero quanto das pessoas que trabalham .

A análise do trabalho nos situa diante dos conflitos recíprocos entre estilos e gêneros. Nas pesquisas de Clot (2006), a ausência ou um enfraquecimento de um gênero profissional tem se mostrado frequentemente na origem dos desregramentos da ação individual mediante os quais é indicada a perda do sentido e da eficácia do trabalho. 
Assim, o conhecimento dos gêneros profissionais mostra-se indispensável à Psicologia do Trabalho se desejamos ter uma oportunidade de transformarcompreender os estilos.

\section{Alguns Caminhos: Intercessões Clínica da Atividade - Cartografia}

Transformar e compreender os processos de trabalho na direção em que estamos indicando significa priorizar, como indicamos ao longo do texto, um olhar para a atividade de trabalho. Assim, para transformar e conhecer os vetores dessa atividade e o entorno que envolve os trabalhadores, os pressupostos da Clínica da Atividade são importantes estratégias para a construção de uma metodologia de análise do trabalho.

A Clínica da Atividade retoma um caminho apontado por Ivar Oddone (citado por Osório da Silva, 2002) de atenção às possibilidades de superação de impasses vividos no trabalho pelos próprios trabalhadores. Uma via que possibilita um deslocamento do cientista da posição de protagonista da investigação e da produção de inovações, incluindo de forma radical a participação dos trabalhadores.

trata-se de fazer uma outra psicologia do trabalho consagrando todos os esforços à busca de um só objetivo: aumentar o poder de ação dos coletivos de trabalhadores sobre o ambiente de trabalho real e sobre si mesmo. A tarefa consiste, então, em inventar ou reinventar os instrumentos desta ação, não mais protestando contra os constrangimentos, mas pela via de sua superação concreta (Clot, 2006, p. 9).

Com esse propósito sugere um dispositivo para essa intervenção clínica que é denominada autoconfrontação. Esse método integra diferentes fases, em que os trabalhadores protagonistas das situações em análise, em princípio, seriam, sucessivamente, confrontados com a sua atividade e posteriormente com a atividade dos outros. Trata-se de uma metodologia fundada em formas de coanálise do trabalho. Conforme Clot (2006), o analista do trabalho é precedido no "campo" por aqueles que nele vivem: sujeitos que já puderam compreender e transformar seu meio de trabalho para lhe dar e/ou conservar um sentido. $\mathrm{O}$ trabalhador elabora o que ele chama de uma "psicologia prática construída pelos trabalhadores", de forma que as avaliações feitas devem ser não só consideradas como incentivadas. Essas avaliações são o enunciado relevante da experiência, que deve servir de ponto de partida a essa análise, pronta para a possibilidade de que essa especialidade genérica se transforme ao longo do caminho. São conhecimentos legítimos e indispensáveis, mas que não podem ser considerados como pontos de vista estabilizados, como formas fechadas em si mesmas, indiferentes ao que pode renovar o gênero a que elas pertencem.

Os trabalhadores passam a ter os psicólogos como interlocutores e a partir dessa interlocução são construídos outros modos de trabalhar-viver. Não se trata de supervalorizar qualquer dos saberes - dos trabalhadores ou dos psicólogos -, a análise não se limita aos conceitos da experiência, que se forja no dia-a-dia do trabalho, nem aos científicos. Produz-se, aqui, um desvio pela análise da atividade, que põe em confronto esses dois conjuntos de conceitos.

Esse método de análise do trabalho é inseparável da elaboração em andamento do próprio método, um caminho que construímos ao trilhá-lo, uma vez que a matéria da análise do trabalho são as transformações da atividade ao longo do tempo, incluindo as transformações que essa análise provoca. Segundo Clot (2006, p. 129) trata-se "não de um método a ser aplicado, mas de uma metodologia de co-análise, re-concebida com eles, a cada vez singular, atendendo às expectativas científicas também”. Nessa direção metodológica, a Clínica da Atividade propõe uma experimentação em autoconfrontação cruzada que tem como objetivo colocar a experiência profissional em discussão. Um ciclo estabelece-se entre aquilo que os trabalhadores fazem e aquilo que eles dizem daquilo que fazem, e por fim, aquilo que eles fazem daquilo que eles dizem (Clot, 2006). Nesse processo de análise, a atividade dirigida em si torna-se uma atividade dirigida para si.

O método consiste em solicitar ao trabalhador que fale sobre seu trabalho, primeiramente para o psicólogo e depois para um colega que tenha a mesma experiência profissional, e, portanto, participa do mesmo gênero profissional. Trata-se não apenas de um meio de explicar aquilo que o trabalhador faz ou aquilo que vê, mas um meio de provocar, de intervir, de levar a pensar, sentir e a agir.

O debate da análise do trabalho é um instrumento de ação. O psicólogo ou o colega participam dos atos e pensamentos do trabalhador, dando visibilidade às realidades do trabalho, na medida em que se retoma a análise com um colega de trabalho com o mesmo nível de especialização. A mudança de destinatário da análise modifica a análise. A atividade de comentário dos dados registrados, que varia conforme se dirija ao psicólogo ou aos colegas, dá um acesso diferente ao real da atividade do sujeito. Ela é em cada caso redirecionada a um determinado destinatário. Os interlocutores não são obstáculos, mas um recurso metodológico.

O sujeito pode encontrar no psicólogo e no colega de trabalho alguma coisa de novo em si mesmo. Ele não o procura em princípio em si mesmo, mas no outro. As diferenças entre os dois destinatários se tornam ferramentas, já que essa metodologia pretende utilizar 
plenamente os recursos da dissonância. Aquilo que o sujeito põe em palavras a partir do debate sobre o vivido na atividade nunca existiu antes nessa forma. Estamos falando de criação, que não é apenas uma memória da vivência anterior.

Nesse processo de coanálise do trabalho, a ação do psicólogo ou do colega em relação à atividade do sujeito é decisiva na produção de um novo trabalhar, que se efetiva na medida em que ele modifica o desenvolvimento possível da ação. Tomamos, assim, as discordâncias advindas dessa confrontação como um instrumento de análise, pois a atividade de linguagem endereçada aos colegas ou ao psicólogo é uma atividade em si, e não só expressão de uma representação do sujeito. O diálogo não funciona com um revelador de um vivido. É uma ação sobre a ação que transforma a experiência vivida possibilitando viver outra experiência. Nosso papel é, portanto, o de acompanhar o desenvolvimento da ação do sujeito e produção de subjetividades que operam neste processo.

Isso porque não entendemos a atividade como algo pronto e acabado, simplesmente a espera de uma explicação, o próprio movimento de análise não a deixa na forma em que está. Ela a transforma. A experiência tem uma história e sua análise transforma essa história. A análise do trabalho pela Clínica da Atividade busca enriquecer a atividade pela interferência que esta sofre em cada contexto de análise. A autoconfrontação não visa, portanto, a uma simples descrição da experiência, mas produz uma nova experiência.

Num método de autoconfrontação as análises se dão enquanto intervimos, enquanto provocamos desvios na atividade e, ao mesmo tempo, o gênero profissional é renovado. Visamos a produzir nos sujeitos bifurcações na encruzilhada das explicações possíveis. Nesses momentos é que se tornam visíveis os conflitos da atividade, mediante os quais nossos interlocutores se defrontam na medida em que se adentram conosco pela análise do trabalho.

Desse modo, a experiência de trabalho habitual pode encontrar outros possíveis para o agir em situação e enriquecer-se ao tomar o gênero num debate coletivo. A experiência pode se desenvolver, ainda, pela confrontação com os conceitos produzidos nas diferentes disciplinas e estes últimos pelo confronto com a atividade prática, que não está pré-constituída nos sujeitos nem é decretada pelo pesquisador. "O sentido da situação analisada surge na relação entre uma situação dada e uma outra situação. Esse fenômeno de produção de sentido é uma experiência corrente". (Clot, 2006, pg 130)

A atividade se transforma junto com o sujeito na medida em que se transforma o próprio gênero profissional. A atividade salta de um gênero para outro: do primeiro gênero de atividade habitual, para o segundo gênero, o da experimentação cruzada, passando pelo gênero científico. Nessas passagens da atividade de um gênero a outro, a atividade, é parte de vários gêneros ao mesmo tempo. Os gêneros exercem uma interferência mútua. Logo, no momento da análise, a atividade é plurigenérica, contribuindo para reavaliar os gêneros que percorre. Nenhum gênero substitui nem suprime os outros. Um retroage sobre os outros: ele os obriga a rever suas possibilidades e limites, a ultrapassá-los.

Então, a ação que pode ser discutida se transforma noutra ação. Estes mecanismos de produção da atividade, entretanto, não são diretamente observáveis, por isso, busca-se o registro de uma marca das ações, que são uma forma de acesso aos conflitos da atividade. Uma forma de nos utilizarmos desses debates sobre a ação que transformam no sujeito sua atividade. $\mathrm{Na}$ autoconfrontação, o registro dos debates e das técnicas da atividade real se mostra como uma opção metodológica bastante produtiva. São utilizados materiais de gravação de sons e imagens que permitem desenvolver tal metodologia de análise do trabalho.

Assim, os trabalhadores deixam de ser apenas observados, passando a analistas do trabalho que desenvolvem, sendo coautores na produção dos dados da pesquisa. Essa direção de análise, que se utiliza de imagens do trabalho, nos indica que o real da atividade ultrapassa a tarefa, e também a própria atividade realizada. Para Clot (2006, p. 133): "O real da atividade é o que se revela possível, impossível ou inesperado no contato com as realidades, não faz parte das coisas que podemos observar diretamente".

Trata-se, portanto, de uma intervenção clínica, uma vez que se interpela o sujeito sobre sua atividade, levando-o a confrontar-se com seu fazer, com os modos como realiza as ações e deixa de realizar outras. Se a análise do trabalho pela Clínica da Atividade prioriza a atividade em curso, acreditamos que o método cartográfico é útil para descrever processos. Tal método nos indica um modo de operar a análise que toma a realidade a ser estudada em sua múltipla composição. A cartografia ao mesmo tempo em que desenha esse processo também o gera e, assim, confere ao trabalho de análise um caráter de intervenção.

Os métodos convencionais que usam questionários, observações, entrevistas estruturadas, servem muito bem às pesquisas científicas que buscam a constatação de fatos já dados e a sustentação de uma realidade pré-estabelecida. O método que apresentamos funciona adequadamente para as análises que abordam a produção de subjetividade e a análise das atividades em curso, ou seja, análises que buscam investigar processos, e, no nosso caso, processos de trabalho. É neste sentido que apostamos na cartografia como estratégia privilegiada para análise do trabalho da forma como o abordamos neste texto. 
Segundo Rolnik e Guattari (1989) a cartografia se refere ao "desenho que acompanha e se faz ao mesmo tempo em que os movimentos de transformação da paisagem". Diferentemente de um geógrafo, comprometido com as formações estáveis e com a produção de mapas topográficos, o cartógrafo acompanha a produção de territórios existenciais, em seus movimentos sempre provisórios e em transformação.

Cartografia, neste caso, acompanha e se faz, ao mesmo tempo, que o desmanchamento de certos mundos - sua perda de sentido - e a formação de outros: mundos que se criam para expressar afetos contemporâneos, em relação aos quais os universos vigentes tornaram-se obsoletos (Rolnik \& Guattari, 1989, p. 15).

Por outro lado, não existe método neutro do ponto de vista teórico, ou seja, todo método tem de alguma forma ser sintonizado com a maneira como você discute os dados, interpreta-os, analisa-os. Enfim, ao discutirmos o problema do método, nos deparamos com uma questão epistemológica: qual é o tipo de relação que o psicólogo estabelece com os mundos do trabalho?

Se não buscamos leis gerais e universais que regem a atividade de trabalho, optamos pela cartografia, que implica uma aliança com o que está em movimento, tendo como foco a multiplicação de possíveis, a produção de subjetividade nos processos de trabalho. $\mathrm{O}$ desafio, então, é formular um método que seja capaz de acompanhar um processo e não de representar um objeto. Desse modo, a cartografia é "uma postura, um princípio ético-estético-política frente ao pesquisar que produz ressonâncias no processo de construção da pesquisa" (Machado, 2007, p. 2). Nessa mesma direção, Kastrup (2007) $)^{5}$, afirma:

A cartografia não é um método para ser aplicado e nem é um conjunto de regras, então, até se prefere dizer: praticar a cartografia, mais do que aplicar a cartografia, enfatizando que a cartografia é uma prática, um conjunto de ações e de gestos, gestos que vão transformando o próprio método. Dessa forma, não é um método que tem um caráter geral. Temos dito também que o método é ad hoc, caso a caso.

Essa é nossa aposta na cartografia: de que ela abra um caminho para as conexões múltiplas e imprevisíveis que venham a se efetuar no processo de experimentação de uma Clínica da Atividade. Assim, para pensarmos as transformações em curso, a cartografia e a clínica como clinamen se aproximam e se potencializam. Ambas nos provocam a sair de nós mesmos e a nos abrir ao que é da ordem do impessoal, da história, do plano do coletivo que nos atravessa. Somos incitados a questionarmos os modos como estamos sendo subjetivados, a não aceitá-los como naturais, a nos colocarmos em desvio; somos levados à construção de agenciamentos coletivos e à desconstrução das certezas e das cristalizações das formas dadas nos mundos do trabalho.

A análise do trabalho deve ser realizada partindo desta experiência compartilhada, na qual conhecer e transformar já não se diferencie. Para isso o conceitoferramenta-intercessor da Clínica como clinamen permite apostar na afirmação da potência inventiva dos próprios trabalhadores para transformarem sua atividade. Se a atividade é algo mais do que a tarefa realizada que coloca os conflitos do real como fazendo parte dessa atividade de trabalho, se ela se faz entre intenções concorrentes, exige atividade criadora frente a um meio em constante variação (Clot, 2006). Então, para realizar o seu trabalho, o trabalhador faz debates, escolhas, improvisações, que convocam a produção de subjetividade no trabalho, a realização de desvios criativos que permitem que a tarefa possa ser realizada - Clínica da Atividade como clinamen.

A função do psicólogo do trabalho é, então, de intervenção, onde a clínica está sempre por ser construída e a análise do trabalho obriga a participação ativa do trabalhador como pesquisador de sua atividade. Estudar a atividade é, também, transformá-la, e envolve mobilização subjetiva, e a metodologia proposta passa a se constituir em pesquisa científica e intervenção no coletivo de trabalho. A partir de um dispositivo comum de trabalho, da atividade real de trabalho, é que os trabalhadores e os investigadores podem, então, começar a pensar coletivamente o trabalho para reorganizá-lo. Como estratégia metodológica, essas ferramentas de investigação - a Cartografia e a Clínica da Atividade - vão se articulando ao longo dessa trajetória, nos apontando para qual direção devemos seguir e auxiliando na construção de questionamentos outros que devem guiar as investigações dos mundos do trabalho.

Finalizamos, então, propondo uma discussão sobre a função do psicólogo do trabalho e suas implicações políticas, o que significa fazer escolhas e "sair do sono letárgico do lugar de especialista, ... assumindo aquele não-lugar, além da medida, em que criar a ação é sempre uma ação possível" (Maia, 2006, p. 7). Trata-se, portanto, de uma postura ética que não pretende definir para os trabalhadores modos subjetivos de existência, modos de trabalhar, isto é, modelos de vida e de trabalhador, mas afirmar a autonomia e a potência de normalização da qual somos capazes, porque vivos, porque produzindo um trabalho vivo.

\section{Notas}

${ }^{1}$ Aqui nos referimos à pesquisa intitulada "Trabalho e Saúde nas Escolas: uma proposta de formação" - fases um e dois - realizada no período 2000-2007, que tem contado com o apoio do CNPq. 
${ }^{2}$ A concepção de vida com a qual trabalhamos nesse artigo referese a uma vida impessoal, uma dimensão vital que, segundo Schérer (2000, p. 21-22), se dá como "puro acontecimento liberado dos acidentes da vida interior e exterior". O autor se refere a uma vida em que a individualidade se apaga em proveito da vida "singular imanente a um homem que não tem mais nome, embora não se confunda com nenhum outro".

${ }^{3}$ Trabalho prazeroso é aquele que cabe ao trabalhador parte importante de sua construção. O sofrimento, a dor está ligada aos sentimentos de "indignidade, de inutilidade e desqualificação" vividas pelos trabalhadores ao executarem uma tarefa aquém de sua capacidade inventiva (Barros \& Barros, 2007).

${ }^{4}$ Os conceitos de gênero e estilo profissionais propostos pela Clínica da Atividade são uma recriação dos conceitos propostos por Bakhtine de gênero e estilo discursivos (Clot, 2006).

${ }^{5}$ Palestra A cartografia como método proferida no Núcleo de Estudos e Pesquisa em Subjetividade e Política do Departamento de Psicologia da Universidade Federal do Espírito Santo. Vitória, ES, 2007.

\section{Referências bibliográficas}

Barros, M. E. B. de \& Barros, R. B. de. (2007). Da dor ao prazer no trabalho. In S. B. Santos-Filho \& M. E. B. de Barros (Orgs.), Trabalhador da saúde: muito prazer! Protagonismo dos trabalhadores na gestão de trabalho em saúde (pp. 61-71). Ijuí: Unijuí.

Barros, R.D. B, Benevides de Barros, R. \& Passos, E. (2001). Clínica e biopolítica na experiência do contemporâneo. Revista Psicologia Clínica, 13(1), 89-100.

Benevides de Barros, R. (2002). Clínica e social: polaridades que se opõem/complementam ou falsa dicotomia? In C. M. Rauter, E. Passos, \& R. Benevides de Barros (Orgs.), Clínica e Política: subjetividade e violação dos direitos humanos (pp. 123-140). Rio de Janeiro: Te Corá/Instituto Franco Baságlia.

Brait, B. (2007). Estilo. In B. Brait (Org.), Bakhtin: conceitos chave (pp. 79-102). São Paulo: Contexto.

Brito, J. \& Athayde, M. (2003). Trabalho, educação e saúde: o ponto de vista enigmático da atividade. Revista Trabalho, Educação e Saúde, 1(2), 239-266.

Clot, Y. (2006). A função psicológica do trabalho. Petrópolis, RJ: Vozes.

Dejours, C. (1994). Psicodinâmica do trabalho. São Paulo: Atlas.

Deleuze, G. \& Parnet, C. (1998). Diálogos. São Paulo: Escuta.

Escossia, L. da \& Kastrup, V. (2005). A concept of collective for overcoming the individual-society dichotomy. Psicologia em Estudo, 10(2). Acesso em 21 de novembro, 2007, em http:// www.scielo.br/scielo.php?script=sci_arttext\&pid=S1413$73722005000200017 \& \operatorname{lng}=\mathrm{en} \& \mathrm{nrm}=\overline{\mathrm{iso}}$

Guattari, F. \& Rolnik, S. (2005). Micropolitica: cartografias do desejo. Petrópolis, RJ: Vozes.

Lourau, R. (1993). René Lourau na UERJ. Análise institucional e prática de pesquisa. Rio de Janeiro: UERJ.

Machado, L. D. (2007). Cartografia. Texto utilizado na Disciplina Metodologia do Programa de Pós-Graduação em Psicologia Institucional da Universidade Federal do Espírito Santo.

Maia, M. A. B. (2006). Corpo invisivel do trabalho: cartografia dos processos de trabalho em saúde. Dissertação de Mestrado, Departamento de Psicologia, Centro de Estudos Gerais, Instituto de Ciências Humanas e Filosofia, Universidade Federal Fluminense, Niterói.
Neves, M. Y., Athayde, M., \& Muniz, H. (2004). Notas sobre saúde mental e trabalho docente a partir de uma investigação com professoras de escolas públicas. In M. Figueiredo, M. Athayde, J. Brito, \& D. Alvarez (Orgs.), Labirintos do trabalho: interrogações e olhares sobre o trabalho vivo (pp. 303-321). Rio de Janeiro: DP\&A.

Oddone, I. et al. (1989). Ambiente de trabalho: a luta dos trabalhadores pela saúde. São Paulo: Hucitec.

Osório da Silva, C. (2002). Vida de hospital: a produção de uma metodologia para o desenvolvimento da saúde do profissional de saúde. Tese de Doutorado, Escola Nacional de Saúde Pública, Fundação Oswaldo Cruz, Rio de Janeiro.

Osório da Silva, C. (2007). Trabalho e perspectivas clínicas. In Anais, 11. Colóquio Internacional de Psicossociologia e Sociologia Clínica, Belo Horizonte, MG. Acessado em dezembro, 2007, em http://www.fafich.ufmg.br/coloquio/files/ Claudia Osorio [140].doc

Pelbart, P. P. Elementos para uma cartografia da grupalidade. Acesso em novembro, 2007, em http://www.rizoma.net/ interna.php?id $=189 \&$ secao $=$ mutacao

Rolnik, S. \& Guattari, F. (1989). Micropolítica e cartografia do desejo. Petrópolis, RJ: Vozes.

Rolnik, S. (2002). Subjetividade antropofágica. In L. D. Machado, M. C. C. Lavrador, \& M. E. B. de Barros (Orgs.), Texturas da psicologia: subjetividade e política no contemporâneo (pp. 11-28). São Paulo: Casa do Psicólogo.

Schérer, R. (2000). Homo Tantum. O impessoal: uma política. In E. Alliez (Org.), Gilles Deleuze: uma vida filosófica (pp. 21-38). São Paulo: Ed. 34.

Schwartz, Y. (2004). Ergonomia, filosofia e exterritorialidade. In F. Daniellou (Coord.), A Ergonomia em busca de seus princípios: debates epistemológicos. São Paulo: Edgar Blücher.

Danielle Vasconcelos Teixeira é mestranda do Programa de Pós-graduação em Psicologia Institucional da UFES e membro do grupo de pesquisa NEPESP - Departamento

de Psicologia/UFES. Endereço para correspondência:

UFES - Departamento de Psicologia. Av. Fernando Ferrari, $n^{\circ}$. 514, Campus Universitário Alaor Queiroz de Araújo, Goiabeiras. CEP: 29075-910. Vitória/ES. E-mail: danipsyche@gmail.com

Maria Elizabeth Barros de Barros é Professora Doutora do Departamento de Psicologia e do Programa de PósGraduação em Psicologia Institucional da Universidade Federal do Espírito Santo. Endereço para correspondência: UFES - Departamento de Psicologia. Av. Fernando Ferrari, $n^{\circ}$. 514, Campus Universitário Alaor Queiroz de Araújo, Goiabeiras. CEP: 29075-910. Vitória/ES. E-mail: betebarros@uol.com.br

\section{Clínica da atividade e cartografia:} construindo metodologias de análise do trabalho Danielle Vasconcelos Teixeira e Maria Elizabeth Barros de Barros

Recebido: 29/02/2008

Revisão: 25/08/2008

Aceite final: 06/09/2008 